\title{
Comparison of bleeding time changes in essential hypertension patients on losartan or amlodipine: a prospective observational study
}

\author{
Narendranath S. ${ }^{1}$, Srinivas LD $^{1}$, Arun S. $^{1}{ }^{*}$, Shashikala $\mathbf{G H}^{1}$, Pallavi MK ${ }^{1}$, \\ Suresh $\mathbf{S R}^{2}$, Imran Maniyar ${ }^{1}$
}

${ }^{1}$ Department of Pharmacology, ${ }^{2}$ Department of Medicine JJM, Medical College, Davanagere577004, Karnataka, India

Received: 30 May 2016

Accepted: 01 July 2016

*Correspondence to:

Dr. Arun S.,

Email: arun72756@gmail.com

Copyright: (C) the author(s), publisher and licensee Medip Academy. This is an openaccess article distributed under the terms of the Creative Commons Attribution NonCommercial License, which permits unrestricted noncommercial use, distribution, and reproduction in any medium, provided the original work is properly cited.

\begin{abstract}
Background: Hypertension leads to vascular damage due to high pressure exerted on arteriolar wall and also promotes atherothrombosis in large and medium sized blood vessels. Thrombosis is an extension of haemostasis and platelets have a crucial role in the formation of atherothrombosis. Increased platelet activity is a risk factor in hypertensive patients and leads to cardio- and cerebrovascular events and target organ damage. Anti-platelet aggregatory treatment in these high risk patients have become a crucial step in their treatment. Recent data indicate that angiotensin II type 1 blockers or AT1 receptor blockers (ARBs) like Losartan and dihydropyridine class of L-type calcium channel antagonist like Amlodipine have anti- platelet activity. These two classes of drugs are frequently administered in hypertensive either alone and in combinations. This study aims to compare the anti-platelet activity of Losartan and Amlodipine. Anti-platelet activity in addition to anti-hypertensive activity of these drugs would be beneficial in treating hypertensive who are at high risk of atherosclerosis and atherothrombosis, if they are selectively prescribed these agents.
\end{abstract}

Methods: This was an observational study. Sixty $(n=60)$ patients diagnosed with essential hypertension, attending medicine outpatient department of a tertiary care hospital were enrolled in the study. Out of them thirty $(n=30)$ were patients who were prescribed losartan. Rest of the patients $(n=30)$ were ones prescribed amlodipine. It was ensured that the patients of both the groups were on respective medication for at least one month. Another thirty $(n=30)$ normotensive subjects acted as control. The bleeding time was evaluated for all three groups using Duke method of bleeding time estimation.

Results: Data was analysed using SPSS software version 20. One way ANOVA was used to analyse the data. This was followed by post hoc Tukey's test. The mean bleeding time(in minutes) of Losartan group was 2.583 $\pm 0.263 \mathrm{SD}$, Amlodipine group was $2.214 \pm 0155 \mathrm{SD}$ and control group was $1.998 \pm 0.198 \mathrm{SD}$. Statistically significant $\mathrm{p}$ value of $<0.001$ was observed in losartan and amlodipine groups.

Conclusions: Our study shows that the mean bleeding time of Losartan group and amlodipine group were significantly higher than that of Control group. It was further observed that the mean bleeding time of losartan was higher than that of amlodipine group indicating a better antiplatelet action by losartan than amlodipine. Additional antiplatelet activity could be desirable to treat hypertensive patients with high atherothrombotic and/or thromboembolic risk.

Keywords: Losartan, Amlodipine, Hypertension, Bleeding time, Antiplatelet activity 


\section{INTRODUCTION}

Essential hypertension is associated with an increased risk of arterial thrombosis. ${ }^{1}$ Increased platelet activity is a significant contributor of this phenomenon and is due to various mechanisms like: endothelial dysfunction resulting from its denudation, overactive sympathetic and renin-angiotensin aldosterone systems, decreased platelet nitric oxide synthesis, and due to platelet degranulation occurring secondary to increased shear. ${ }^{1,2}$ Nitric oxide (NO) is synthesized from L-arginine by the enzymes known as nitric oxide synthases (NOS). The 3 isoforms of NOS are: NOS1 [neuronal NOS (nNOS)], NOS2 [inducible NOS (iNOS)] and NO3 [endothelial NOS (eNOS)]. NOS1 and NOS3 are always expressed in cells and their enzymatic activity is regulated by intracellular $\mathrm{Ca} 2+$. NOS2 is not present in resting cells and presence of inflammatory stimuli is required to induce it. Its activity is $\mathrm{Ca} 2+$ independent. It has been found that NOS2 and NOS3 are expressed in platelets. ${ }^{3}$ Physiologically, in an intact vasculature, circulating platelets are maintained in an inactive state by NO and prostacyclin (PGI2) released by endothelial cells lining the blood vessels. ${ }^{4} \mathrm{NO}$ has a significant role in the regulating vascular tone and in the controlling blood pressure. Various studies point out that reduction in normal basal NO release may predispose to hypertension, thrombosis, atherosclerosis and vasospasm. It has been found that Inhibition of eNOS elevates blood pressure in healthy humans and in mice disruption of eNOS gene leads to hypertension. ${ }^{5}$ In hypertension, shear due to increased pressure can cause endothelial damage as the mechanisms of normal vascular remodeling is faulty due to impaired structural adaptation to elevated blood pressure and vasoconstriction. ${ }^{6,7}$ When the vessel wall is damaged, sub endothelial matrix is exposed and platelets adhere to collagen with the help of $\alpha 2 \beta 1$ and glycoprotein(GP)V1 and to Von Williebrand factor (vWF) with the help of GPIb $\alpha$ and GPIIb/IIIa present on the platelet surface. Adherent platelets secrete ADP from their dense granules, and synthesize and release thromboxane A2 (TXA2). ADP and TXA2 are platelet agonists and activate more platelets to the site of vascular injury. Activated platelets also potentiate coagulation by binding to clotting factors that lead to thrombin generation. Thrombin converts fibrinogen to fibrin and is also a potent platelet agonist. ${ }^{1}$ Hence platelets have an important role in formation of atherothrombosis in hypertensives and contribute to cardio-and cerebrovascular events leading to target organ damage. , $^{6,8}$ Anti-platelet treatment in hypertensives with high risk of thromboembolic and/or atherosclerosis is an established step in their treatment. ${ }^{9}$ Recent data indicate that angiotensin II type 1 blockers or AT1 receptor blockers (ARBs) like losartan and dihydropyridine class of L-type calcium channel antagonist like Amlodipine have antiplatelet activity. ${ }^{10-12}$ These two classes of drugs are frequently administered in hypertensive either alone and in combinations. ${ }^{8,13}$ Anti-platelet activity in addition to anti-hypertensive activity of these drugs would be beneficial in treating hypertensive who are at high risk of atherosclerosis and atherothrombosis, if they are selectively prescribed these agents. ${ }^{10}$ The present study aims to compare the antiplatelet activity of these two drugs in patients with essential hypertension. Bleeding time is a laboratory test that can be used to assess platelet function. ${ }^{14,15}$ So an increase in bleeding time can be a function of reduced platelet activity possibly by antiaggregatory action. Duke method of bleeding time estimation was used in this study. ${ }^{14,15}$

\section{METHODS}

It was an observational study. A total of $(n=60)$ patients diagnosed with essential hypertension attending Medicine outpatient department of a tertiary care hospital were enrolled in the study. Among them group I consisted of thirty $(n=30)$ patients who were prescribed Losartan. Rest of the thirty $(n=30)$ in group II were on Amlodipine. Thirty $(n=30)$ normotensive subjects taken as control and belonged to Group III. Initial baseline characteristics like SBP, DBP, age, sex, duration of treatment, average dose of drug used, average duration of treatment were recorded. Detailed written informed consent was taken from all study subjects. Subjects included in study were $\geq$ 18 years of age and of both sexes. Losartan and Amlodipine groups only included patients who received their respective drug for at least a period of one month. Patients with secondary hypertension, suffering from fever, comorbid bleeding disorders, any medication altering platelet function like aspirin, dipyridamole, statins etc., pregnant and lactating women were excluded from the study. Duke method of Bleeding time estimation was used to assess changes in Bleeding time in all the groups. ${ }^{14,15}$ One Staff in the lab was trained for performing the test and recorded all the results. Lancet was used to prick left fingertip and a filter paper was used to wipe the blood every 15 seconds till the bleeding stops. Results were simultaneously observed and recorded by one investigator and on finding a difference in observed value mean was taken as the bleeding time.

\section{Statistical analysis}

All the data was expressed as mean \pm SD. One way ANOVA was used to compare the observed bleeding time of all groups. This was followed by post hoc Tukey's test. A p value of $<0.05$ was considered statistically significant. Statistical calculations were performed using SPSS Software version 20.

\section{RESULTS}

The baseline characteristics are represented in Table 1. As shown in Table 2, the mean bleeding time(in minutes) of Losartan group was 2.583 $\pm 0.263 \mathrm{SD}$, Amlodipine group was $2.214 \pm 0155 \mathrm{SD}$ and control group was $1.998 \pm 0.198$ SD. Statistically significant $p$ value of $<0.001$ was observed in all the groups. However, the mean bleeding time of losartan group (group I) $2.583 \pm 0.048 \mathrm{SD}$ was 
more than that of amlodipine group (group II) $2.214 \pm 0.028 \mathrm{SD}$. The difference in bleeding time was statistically significant with a $p$ value of $<0.001$. Figure 1 shows the bar diagram representing the changes in mean bleeding time with SD of all the groups.

Table 1: Baseline characteristics of subjects.

\begin{tabular}{|lcll|}
\hline & $\begin{array}{l}\text { Group I } \\
\text { (losartan) }\end{array}$ & $\begin{array}{l}\text { Group II } \\
\text { (amlodipine) }\end{array}$ & $\begin{array}{l}\text { Group III } \\
\text { (control) }\end{array}$ \\
\hline $\begin{array}{l}\text { Age } \\
\text { (in years) }\end{array}$ & 53.067 & 54.8 & 51.933 \\
\hline Sex & & & \\
\hline $\begin{array}{l}\text { Males } \\
\text { Females }\end{array}$ & 17 & 16 & 15 \\
\hline SBP & 129.667 & 130 & 15 \\
\hline DBP & 86.667 & 84.667 & 83.333 \\
\hline $\begin{array}{l}\text { Average } \\
\text { dose } \\
\text { (mg/day) }\end{array}$ & 28.33 & 6.66 & - \\
\hline $\begin{array}{l}\text { Average } \\
\text { Duration of } \\
\text { treatment } \\
\text { (in years) }\end{array}$ & 2.75 & 3.683 & - \\
\hline
\end{tabular}

Table 2: Mean bleeding time (BT) \pm SD of losartan, amlodipine and control group.

\begin{tabular}{|lll|}
\hline & Mean BT(in minutes) & SD \\
\hline Group I (losartan)* & 2.583 & 0.263 \\
\hline Group II & 2.214 & 0.155 \\
(amlodipine)* $_{\text {Group III (control) }}$ & 1.998 & 0.198 \\
\hline
\end{tabular}

*Statistically significant $\mathrm{p}$ value of $<0.001$.

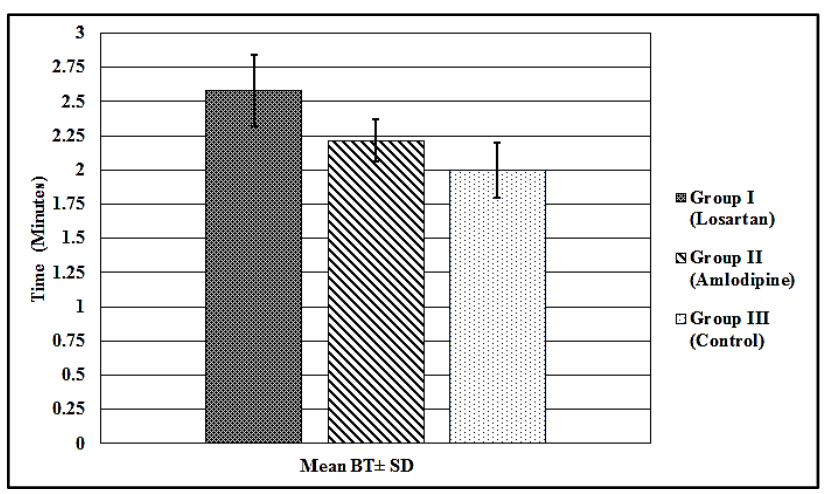

Figure 1: Bar diagram representing BT changes of losartan, amlodipine and control group.

\section{DISCUSSION}

Our study shows that the mean bleeding time of Losartan group was higher than that of Amlodipine indicating a better antiplatelet action by losartan. Angiotensin II type 1 antagonist or angiotensin receptor blockers (ARBs) and calcium channel blockers are commonly prescribed in hypertension. European society of hypertension and european society of cardiology (ESH/ESC) 2013 guidelines recommend the use of these agents. ${ }^{13}$ In addition to lowering blood pressure they are known to have antiplatelet activity. Amlodipine belongs to dihydropyridine class of L-type calcium channel blockers. Platelets do not have L-type calcium channels but these agents exhibit antiplatelet activity nonetheless. Exact mechanism of action is not completely elucidated. Activation of NO/cGMP- dependant signalling pathway is one of the proposed mechanisms of anti-platelet activity. ${ }^{12}$ Amlodipine can cause release of endothelium derived NO. It is found that amlodipine can phosphorylate eNOS through protein kinase $\mathrm{C}(\mathrm{PKC})$ pathway and enhance its functions. ${ }^{16} \mathrm{NO}$ thus formed binds to soluble guanylyl cyclase (sGC) which is a receptor for NO and converts GTP to cGMP. ${ }^{17}$ cGMP acts through cyclic GMP dependant protein kinase $1 \beta$ (PKG1 $\beta$ ). PKG1 $\beta$ is predominantly present in platelets. ${ }^{12,18}$ NO mediated increase in cGMP inhibits platelet aggregation. ${ }^{19}$ PKG1 promotes increased storage of $\mathrm{Ca} 2+$ in sarcoplasmic reticulum and inhibits inositol 1,4,5-tris phosphate stimulated $\mathrm{Ca} 2+$ release from sarcoplasmic reticulum. This results in decreased intracellular $\mathrm{Ca} 2+$ levels in platelets. Calcium is required for platelet activation and function. Decrease in intracellular $\mathrm{Ca} 2+$ in turn decreases platelet activation. PKG also inhibits TXA2 by phosphorylation. $^{12,18}$

Another study suggests antiplatelet activity of Amlodipine through PPAR $\beta$ agonistic activity. ${ }^{20}$ Even though platelets are unucleated, they contain transcription factors like peroxisome proliferator-activated receptor (PPAR). Activation of PPARs inhibited platelet activation through a non-genomic mechanism and also increases NOS expression.

Inhibition of human platelet thromboxane A2/Prostaglandin $\mathrm{H} 2$ is the possible mechanism of action of losartan. Thromboxane A2 is a potent inducer of platelet aggregation. Physiologically platelet cAMP levels are regulated by TXA 2 and PGI2. Increased intracellular concentration of cAMP in platelets activates protein kinase. A which through incompletely elucidated mechanism causes a decrease in intracellular calcium in platelets which in turn decrease platelet aggregability. The exact mechanism by which increased cAMP leads to decreased platelet aggregation is unknown as of yet. ${ }^{20}$

Antiplatelet aggregation of these agents could be of additional benefit in hypertensive patients and is desirable to treat hypertensive patients with high atherothrombotic and/or thromboembolic risk. ${ }^{10}$

\section{CONCLUSIONS}

Our study shows that the mean bleeding time of losartan group and amlodipine group were significantly higher than that of control group. It was further observed that the mean bleeding time of losartan was higher than that of amlodipine group indicating a better antiplatelet action by 
losartan than amlodipine. Additional antiplatelet activity could be desirable to treat hypertensive patients with high atherothrombotic and/or thromboembolic risk.

\section{ACKNOWLEDGEMENTS}

My sincere gratitude to department of medicine JJM Medical College. I would like to thank Central Lab JJM Medical College and the subjects of this study for their co-operation.

\section{Funding: No funding sources}

Conflict of interest: None declared

Ethical approval: The study was approved by the Institutional Ethics Committee

\section{REFERENCES}

1. Gkaliagkous E, Passacquale G, Douma S, Zamboulis C, Ferro A. Platelet activation in essential hypertension: implications for antiplatelet treatment. Am J Hypertens. 2010;23(3):229-36.

2. Sato Y, Fuji S, Imagawa S, Ohmura K, Ohmura Y, Andoh Y, et al. Platelet aggregability in patients with hypertension treated with angiotensin II type 1 receptor blockers. J Atheroscler Thromb. 2007;14(1):31-5.

3. Cozzi MR, Guglielmini G, Battistin M, Momi S, Lombardi E, Miller EC, et al. Visualization of nitric oxide production by individual platelets during adhesion in flowing blood. Blood. 2015;125(4):697705.

4. Harrison T, Kasper D, Fauci A, Hauser S, Longo D, Jameson J, et al. Editors Harrison's: principle of internal medicine. $19^{\text {th }}$ ed. New York (USA): McGraw Hill Education; 2015:745.

5. Shankarishan P, Bora PK, Ahmed G, Mahanta J. Endothelial nitric oxide synthase gene polymorphisms and the risk of hypertension in an Indian population. Bio Med Research International. 2014(2014):1-11.

6. Yang GJ. Antiplatelet therapy in patients with hypertension. Journal of Translational Internal Medicine. 2013;1(1):28.

7. Radu D, Rudic, Sessa WC. Human genetics'99: the cardiovascular system nitric oxide in endothelial dysfunction and vascular remodeling: clinical correlates and experimental links. Am J Hum Genet. 1999;64:673-7.

8. Richard AP, Wenche JY, Joaquin JJ, Lucia MM, Lawrence LH, Madelyn V, et al. Effects of severe hypertension on endothelial and platelet microparticles. Hypertension. 2003;41:211-7.
9. Kalinowski L, Matys T, Chabielska E, Buczko W, Malinski T. Angiotensin II AT1 receptor antagonists inhibit platelet adhesion and aggregation by NO release. Hypertension. 2002;40:521-7.

10. Sakamoto T, Kudoh T, Sakamoto K, Matsui K, Ogawa H. Antithrombotic effects of losartan in patients with hypertension complicated by atrial fibrillation. Hypertension Research. 2014;37:513-8.

11. Monton M, Jimenez A, Nunez A, Lopez-Blaya A, Farre J, Gomez J, et al. Comparative effect of angiotensin II AT-type-1 receptor antagonists in vitro on human platelet activation. $\mathbf{J}$ Cardiovasc Pharmacol. 2000;35(6):906-13.

12. Tz-Chong C. New mechanisms of antiplatelet activity of nifedipine, an L-type calium channel blocker. BioMedicine. 2014;4(3):17-24.

13. Mancia G, Fagard R, Narkiewicz K. ESH/ESC guidelines for the management of arterial hypertension: the task force for the management of arterial hypertension of the European Society of Hypertension (ESH) and of the European Society of Cardiology (ESC). Eur Heart J. 2013;34(28):2159219.

14. Charbek E. Bleeding time: reference range, interpretation, collection and panels; 2016. Available at http://emedicine.medscape.com/article/2085022overview.

15. Kumar V, Abbas AK, Aster JC. Robbins: basic pathology. $9^{\text {th }}$ ed. Philadelphia (PA): Elsevier Saunders; 2013:450.

16. He Y, Si D, Yang C, Wi L, Li B, Ding M. The effects of amlodipine and $\mathrm{S}$ (-)-amlodipine on vascular endothelial function in patients with hypertension. Am J Hypertens. 2014;27(1):27-31.

17. Lincoln RP. Guanylyl cyclase structure function and regulation. Cell Signal. 2011;23(12):1921-6.

18. Thiriet M. Biomathematical and biomechanical modeling of circulatory and ventilator systems 4 : intracellular signalling mediators in the circulatory and ventilator systems. USA (NY): Springer Science+Business Media; 2013:846.

19. Golan DE, Tashjian AH, Armstrong EJ, Armstrong AW. Editors principles of pharmacology: the pathophysiologic basis of drug therapy. $3^{\text {rd }}$ ed. Philadelphia (PA). Lippincott Williams and Wilkins; 2012:362.

20. Shih CY, Lin IH, Ding JC, Chen FC, Chou TC. Antiplatelet activity of nifedipine is mediated by inhibition of $\mathrm{NF}-\kappa \mathrm{B}$ activation caused by enhancement of PPAR- $\beta /-\gamma$ activity. Br J Pharmacol. 2014;171(6):1490-500.

Cite this article as: Narendranath $\mathrm{S}$, Srinivas LD Arun S, Shashikala GH, Pallavi MK, Suresh SR, et al. Comparison of bleeding time changes in essential hypertension patients on losartan or amlodipine: a prospective observational study. Int J Basic Clin Pharmacol 2016;5:1555-8. 